\title{
The Effect of CoFe204, CuFe2O4 and Cu/CoFe2O4 Nanoparticles on the Optical Properties and Piezoelectric Response of the PVDF Polymer.
}

Mai EL-Masry ( $\sim$ mai.elmasry@thebes.edu.eg )

Higher Engineering Institute https://orcid.org/0000-0002-2681-0883

Rania Ramadan

Cairo University

\section{Research Article}

Keywords: Pizoelectric, PVDF, PFM, Cobalt ferrite, Copper ferrite, cobalt doped copper ferrite, nanoparticles.

Posted Date: September 1st, 2021

DOl: https://doi.org/10.21203/rs.3.rs-853775/v1

License: (c) (i) This work is licensed under a Creative Commons Attribution 4.0 International License.

Read Full License 


\section{Conflict of Interest and Authorship Conformation Form}

\section{Manuscript title:}

The effect of $\mathrm{CoFe}_{2} \mathrm{O}_{4}, \mathrm{CuFe}_{2} \mathrm{O}_{4}$ and $\mathrm{Cu} / \mathrm{CoFe}_{2} \mathrm{O}_{4}$ nanoparticles on the Optical properties and piezoelectric response of the PVDF polymer.

\section{The authors whose names are listed immediately below certify that:}

$\checkmark \quad$ All authors have participated in (a) conception and design, or analysis and interpretation of the data; (b) drafting the article or revising it critically for important intellectual content; and (c) approval of the final version.

$\checkmark$ This manuscript has not been submitted to, nor is under review at, another journal or other publishing venue.

$\checkmark \quad$ The following authors have affiliations with organizations with direct or indirect financial interest in the subject matter discussed in the manuscript:

\begin{tabular}{cc}
\hline Author's name & Affiliation \\
\hline Mai M. El-Masry & $\begin{array}{c}\text { Basic Science Dept., Higher Engineering Institute, } \\
\text { Thebes Academy, Cairo, Egypt }\end{array}$ \\
\hline Rania Ramadan & $\begin{array}{c}\text { Materials Science Lab. (1), Physics Department, } \\
\text { Faculty of Science, Cairo University, Giza, Egypt }\end{array}$ \\
\hline
\end{tabular}




\title{
The effect of $\mathrm{CoFe}_{2} \mathrm{O}_{4}, \mathrm{CuFe}_{2} \mathrm{O}_{4}$ and $\mathrm{Cu} / \mathrm{CoFe}_{2} \mathrm{O}_{4}$ nanoparticles on the Optical properties and piezoelectric response of the PVDF polymer
}

\author{
Mai M. El-Masry ${ }^{(a)}$, Rania Ramadan ${ }^{(b)}$ \\ ${ }^{a}$ Basic Science Dept., Higher Engineering Institute, Thebes Academy, Cairo, Egypt \\ ${ }^{\mathrm{b}}$ Materials Science Lab. (1), Physics Department, Faculty of Science, Cairo University, \\ Giza, Egypt
}

\begin{abstract}
Cobalt ferrite, Copper ferrite and cobalt doped copper ferrite nanoparticles have been synthesized and characterized using different characterization methods (XRD, FTIR and FESEM). The prepared nanoparticles have been used as promising fillers of the polyvinylidene fluoride (PVDF) polymer. The $\mathrm{PVDF} /\left(\mathrm{Cu}-\mathrm{CoFe}_{2} \mathrm{O}_{4}, \mathrm{CoFe}_{2} \mathrm{O}_{4}\right.$, and $\left.\mathrm{CuFe}_{2} \mathrm{O}_{4}\right)$ nanocomposites films have been prepared via a simple solution casting technique. The optical properties and the piezoelectric response of the prepared nanocomposite films have been studied. The study showed that $\mathrm{Cu}-$ $\mathrm{CoFe}_{2} \mathrm{O}_{4}, \mathrm{CoFe}_{2} \mathrm{O}_{4}$, and $\mathrm{CuFe}_{2} \mathrm{O}_{4}$ have enhanced the interfacial polarization density and dielectric constant. The optical conductivity value of $\mathrm{PVDF} /\left(\mathrm{Cu}-\mathrm{CoFe}_{2} \mathrm{O}_{4}\right.$ and $\left.\mathrm{CoFe}_{2} \mathrm{O}_{4}\right)$ increased five times compared with the pure PVDF. Also, an increase in the piezoelectric response has been recorded by adding the nano-fillers to the pure PVDF.
\end{abstract}

Keywords:

Pizoelectric, PVDF, PFM, Cobalt ferrite, Copper ferrite, cobalt doped copper ferrite, nanoparticles.

Address correspondence to E-mail: mai.elmasry@thebes.edu.eg 


\section{1- Introduction}

The energy harvesting or renewable energies, such as solar energy, wind energy, vibrational energy and ocean energy, as an alternative to the traditional energy have been exploited owing to their sustainability and environment-ecofriendly [1].One of the most important energy harvesting energies is piezoelectric technology. Piezoelectric materials could transfer energy between electric field and force field. Piezoelectric polymer has been used as an excellent piezoelectric material for its excellent piezoelectricity and flexibility [2]. Compared with other polymer materials such as nylon and polyvinyl chloride, polyvinylidene fluoride (PVDF) has better piezoelectric properties. (PVDF) is a low-density, non-reactive, easier to process, light weight, chemical stability, tractability, readily tunable properties and resilient weathering characteristics and has the much lower price [3] [4] [5]. The PVDF films are very flexible, it can be compatible with every kind of matrix material. PVDF conductive fillers including metal nanoparticles, carbon nanotubes, and carbon fibers have recently been employed to prepare higher composite materials based on the percolation phenomenon [6] [7].

PVDF is not only piezoelectric, but it also has excellent pyroelectric, flexoelectric and dielectric properties. Ferroelectric materials could be considered a subclass of piezoelectric, a class of dielectric materials, and pyroelectric materials. Ferro electricity is the property in which certain materials can possess a spontaneous electric polarization that can be reversed by the application of external electric field yielding a hysteresis loop [8]. A lot of various works have been carried out in exploring ferroelectric materials and their applications, like the ferroelectric field-effect transistor, ferroelectric random-access memory, piezoelectric sensors, etc [8].

The present work aims to obtain a new nanocomposite film which are quite flexible, freestanding and combines the excellent properties exhibited by both PVDF and the prepared nanoparticles. Consequently, PVDF films were prepared by a simple solution casting technique [9] selecting dimethyl formamide (NMP) as the solvent while, $\mathrm{CoFe}_{2} \mathrm{O}_{4}, \mathrm{CuFe}_{2} \mathrm{O}_{4}$ and $\mathrm{Cu}-\mathrm{CoFe}_{2} \mathrm{O}_{4}$ nanoparticles have been used as the fillers. The influence of the PVDF fillers on the optical properties, dielectric constant, and piezoelectric response are investigated. 


\section{Experimental techniques}

\subsection{Materials}

Poly (vinylidene fluoride) (PVDF) powder, N-Methyl-2-Pyrrolidone (NMP, 99.5\% of purity) (Merk Chemical, India), iron nitrate $\mathrm{Fe}\left(\mathrm{NO}_{3}\right)_{3} \cdot 9 \mathrm{H}_{2} \mathrm{O}(99 \%)$, cobalt nitrate $\mathrm{Co}\left(\mathrm{NO}_{3}\right)_{2} \cdot 6 \mathrm{H}_{2} \mathrm{O}$, copper nitrate $\mathrm{Cu}\left(\mathrm{NO}_{3}\right)_{2} \cdot 6 \mathrm{H}_{2} \mathrm{O}(99 \%)$ and citric acid $\left(\mathrm{C}_{6} \mathrm{H}_{8} \mathrm{O}_{7}\right)$, were used as metal precursors. All materials Were purchased from (Sigma Aldrich, USA).

\subsection{Samples preparation methods}

\subsubsection{Nano powder preparation}

$\mathrm{CoFe}_{2} \mathrm{O}_{4}, \mathrm{CuFe}_{2} \mathrm{O}_{4}$ and $\mathrm{Cu}-\mathrm{CoFe}_{2} \mathrm{O}_{4}$ nanoparticles were synthesized using the citrate autocombustion method. This includes weighing the stoichiometric ratios of cobalt nitrate, copper nitrate, iron nitrate as well as citric acid had been dissolved with a small amount of distilled water under vigorous stirring. Then the $\mathrm{pH}$ value of the solution had been adjusted at 7 . The temperature was raised up to $250{ }^{\circ} \mathrm{C}$ until all fumes ended. The resultant powder was calcined for $4 \mathrm{~h}$ at $800{ }^{\circ} \mathrm{C}$ with a rate of $4{ }^{\circ} \mathrm{C} / \mathrm{min}$.

\subsection{2. ( $\mathrm{PVDF} / \mathrm{CoFe}_{2} \mathrm{O}_{4}, \mathrm{CuFe}_{2} \mathrm{O}_{4}$ and $\mathrm{Cu}-\mathrm{CoFe}_{2} \mathrm{O}_{4}$ ) film preparation}

4 samples of PVDF solution were prepared. Each sample was prepared by dissolving 3gm of PVDF powder in 10mL. of (NMP) at room temperature under continuous stirring for $12 \mathrm{~h}$. Till, the resulting solution (PVDF/NMP) became transparent. Afterwards, 3 milligrams of the $\mathrm{CoFe}_{2} \mathrm{O}_{4}, \mathrm{CuFe}_{2} \mathrm{O}_{4}$ and $\mathrm{Cu}$ $\mathrm{CoFe}_{2} \mathrm{O}_{4}$ nanoparticles added to 3 samples of the (PVDF/NMP) solutions and kept under magnetic stirring for $2 \mathrm{~h}$. The fourth sample kept as prepared. Finally, each sample was poured on a clean glass surface on a hotplate kept at $60^{\circ} \mathrm{C}$ until the solidification of the solution film. The obtained films of $(2 \times 2.2 \mathrm{~mm})$ washed using distilled water to remove any contaminating particles and for full solidification of the films.

\subsection{Nanoparticle's characterization}

The crystalline phases of $\mathrm{CoFe}_{2} \mathrm{O}_{4}, \mathrm{CuFe}_{2} \mathrm{O}_{4}$ and $\mathrm{Cu}-\mathrm{CoFe}_{2} \mathrm{O}_{4}$ nanoparticles were identified by Fourier Transform Infrared Spectroscopy (FT-IR) instrument (Perkin Elmer) in the range of 4000-400 $\mathrm{cm}^{-1}$. To investigate the degree of crystallinity, X-ray diffraction (XRD) analysis was carried out using a Bruker, D8 Advance, X-ray diffractometer, operating at $40 \mathrm{kV}$ and $40 \mathrm{~mA}$ of current with $\mathrm{Cu}-\mathrm{Ka}$ 
radiation $(\lambda=1.541 \AA$ ). Field emission scanning electron microscopy (FESEM) JEM-ARM300F operated at $200 \mathrm{kV}$ was used for topographical investigation of the prepared nanoparticles.

\subsection{Optical investigations}

UV-vis transmission and reflection spectra were recorded for estimating the optical properties of the prepared nanocomposite films using (JASCO Corp., V-570, Rev. 1.00) spectrometer.

\subsection{Piezoelectric response}

\subsubsection{Digital storage oscilloscope}

The generated voltage by repeating human finger press and release on the surface of the investigated nanocomposite films has been recorded using a digital storage oscilloscope [GW Instek Gos-806s]. The responses were recorded in terms of open circuit output voltage, at room temperature.

\subsubsection{Piezoresponse Force Microscopy (PFM)}

PFM measurements were performed using a commercial Flex-Axiom AFM, head type FlexAFM with 115-135 $\mu \mathrm{m}$ length, nominal spring constant of $5 \mathrm{~N} / \mathrm{m}$, Co-Cr coated tip with electrical resistivity of $0.01-0.025 \Omega \cdot \mathrm{cm}$, tip curvature radius $\sim 35 \mathrm{~nm}$ and nominal resonance frequency of $165.08 \mathrm{kHz}$. In order to measure the piezoresponse of the samples, an a.c. voltage was applied to the tip, at a frequency of $165.08 \mathrm{kHz}$. Scan rate was $0.5 \mathrm{~Hz}$ and the scan area was $(250 \times 250) \mathrm{nm}^{2}$. All measurements were performed in an insulating chamber at room temperature.

\section{Results and discussion}

\subsection{Nanoparticles characterization}

\subsubsection{XRD}

Fig. (1) illustrates the XRD patterns of $\mathrm{CoFe}_{2} \mathrm{O}_{4}, \mathrm{CuFe}_{2} \mathrm{O}_{4}$ and $\mathrm{Cu}-\mathrm{CoFe}_{2} \mathrm{O}_{4}$ powder. The XRD results of all the prepared samples match with the reported standard phase in the XRD reference ICDD card. The average crystallite size of prepared samples was calculated using the X-ray line broadening method via the Scherrer equation [10]

$$
D=\frac{k \lambda}{\beta \cos \theta} \ldots \ldots(1)
$$


Where, D is the crystallite size (nm), $K$ is the particle shape factor (0.9), $\lambda$ is the target wavelength (nm), $\beta$ is the corrected full width at half maximum, and $\theta$ is the position (angle) of the peak at the maximum. The estimated crystallite sizes are 19.1, 24.1 and 22.2 for the $\mathrm{CoFe}_{2} \mathrm{O}_{4}, \mathrm{CuFe}_{2} \mathrm{O}_{4}$ and $\mathrm{Cu}-\mathrm{CoFe}_{2} \mathrm{O}_{4}$ nanoparticles, respectively.

\subsubsection{FTIR}

Fig. (2) illustrates the FTIR spectra of $\mathrm{CoFe}_{2} \mathrm{O}_{4}, \mathrm{CuFe}_{2} \mathrm{O}_{4}$ and $\mathrm{Cu}-\mathrm{CoFe}_{2} \mathrm{O}_{4}$ nanoparticles which recorded in the range $4000-400 \mathrm{~cm}^{-1}$. From the fig. it can be noted that the band at $1108 \mathrm{~cm}^{-1}$ related to the residual Fe-OOH. Bands present at about $537.9 \mathrm{~cm}^{-1}$ and $471 \mathrm{~cm}^{-1}$ are associated with the stretching vibrations of metal oxide in octahedral group complex Co (II)- $\mathrm{O}_{2}-$ and $\mathrm{Fe}$ (III) $-\mathrm{O}_{2}-$ tetrahedral group [11]. $534.97 \mathrm{~cm}^{-1}$, and $430.2 \mathrm{~cm}^{-1}$ could be ascribed to vibrations of M-O (M denoted to copper or iron) [12]. Generally, the transmittance bands in the region $400-600 \mathrm{~cm}^{-1}$ confirm the existence of copper ferrites. Moreover, the band $v_{1}$ that is observed around $526 \mathrm{~cm}^{-1}$ is assigned to the intrinsic stretching vibration of metal cations in tetrahedral sites while the band $v_{2}$ that is located at $466 \mathrm{~cm}^{-1}$ is attributed to the stretching vibration of oxygen bonds in the B sites [13] [14].

\subsubsection{FESEM}

The FESEM micrographs shown in Fig. (3: a-c) of $\mathrm{CoFe}_{2} \mathrm{O}_{4}, \mathrm{CuFe}_{2} \mathrm{O}_{4}$ and $\mathrm{Cu}-\mathrm{CoFe}_{2} \mathrm{O}_{4}$ respectively showed a homogenous distribution of polycrystalline nanometer particles. The present particles showed agglomeration where some particles form large clusters.

\subsection{Optical properties}

Fig. (4) shows the variation of the reflectance of UV-Vis. Spectrum of $\mathrm{CoFe}_{2} \mathrm{O}_{4}, \mathrm{CuFe}_{2} \mathrm{O}_{4}$ and $\mathrm{Cu}$ $\mathrm{CoFe}_{2} \mathrm{O}_{4}$ powder with the wavelength. From the fig. it can be observed that the reflectance values increasing with increasing wavelength values. Also, the PVDF has decreased the reflectance values of the prepared nanocomposite films with an intensive peak at $854 \mathrm{~nm}$. were observed in Fig. (5, a).

Fig. (5, b) shows the change in transmittance of pure PVDF and PVDF/ $\left(\mathrm{CoFe}_{2} \mathrm{O}_{4}, \mathrm{CuFe}_{2} \mathrm{O}_{4}\right.$ and $\mathrm{Cu}-$ $\mathrm{CoFe}_{2} \mathrm{O}_{4}$ ) nanocomposites with the wavelength $(\lambda)$. From the fig. it can be noted that the transmittance of PVDF decreases with the addition of nanoparticles especially with the $\mathrm{CoFe}_{2} \mathrm{O}_{4}$ and $\mathrm{Co}-\mathrm{CuFe}{ }_{2} \mathrm{O}_{4}$ samples. The decrease in transmittance observed for nanocomposite samples is attributed to light scattering caused by the $\mathrm{CoFe}_{2} \mathrm{O}_{4}, \mathrm{CuFe}_{2} \mathrm{O}_{4}$ and $\mathrm{Cu}-\mathrm{CoFe}_{2} \mathrm{O}_{4}$ nanoparticles. 
Moreover, fig. (5, a) and fig. (6, a) have been showed significant increase in the reflectance and absorbance coefficient percentages of the prepared nanocomposite films compared with the pure PVDF. The absorption coefficient $(\alpha)$ of the investigated samples has been determined by the following equation [15].

$\alpha=\frac{2.303 A}{l} \quad \ldots(2)$, where A: absorbance $l$ : thickness of the specimen.

The very high absorbance in the UV region for the investigated films makes them of interest in UV protection applications [16]. The curves in Fig. $(6$, a) demonstrate a clear peak in the UV region at $\lambda \approx$ $230 \mathrm{~nm}$ for both pure and doped PVDF which is corresponding $\pi-\pi^{*}$ transitions of aromatic C-C bonds [17]. Also, the PVDF/CoFe ${ }_{2} \mathrm{O}_{4}$ and PVDF/ Co- $\mathrm{CuFe}_{2} \mathrm{O}_{4}$ samples showed a high reflectance peak at the near infrared region of $\lambda \approx 854 \mathrm{~nm}$.

Fig. $(5, b)$ indicates the increase in the extinction coefficient $(K)$ as the nanoparticles added to PVDF. The extinction coefficient is the measure of fraction of light lost because of scattering and absorption per unit distance of penetration medium. The extinction coefficient $(\mathrm{K})$ is given by the following equation [15]: $\mathrm{K}=\alpha \lambda / 4 \pi$....(3) , $\alpha$ is percentage absorption coefficient, and $\lambda$ is wavelength.

The refractive index is Another mainly important elemental property of material because of its direct relationship with the electronic polarizability of ions and the local field in the optical material. The refractive index (n) of composite materials has been calculated via given equation [18],

$$
n=\frac{1}{T_{s}}+\sqrt{\frac{1}{T_{s}}-1} \ldots . .(4), \text { where } \mathrm{T}_{\mathrm{s}} \text { is } \% \text { transmission coefficient. }
$$

Fig. (7) shows the variation of the refractive index $\mathbf{n}$ versus $\lambda$ for all investigated samples. A significant increase in the refractive index $n$ was observed in the samples by the addition of the nanoparticles to the PVDF polymer. This increase can be attributed to the intermolecular chemical and physical interaction between the filler and the adjacent PVDF chain segments which lead to enhance the density of the films resulting in higher refractive indices. The decreasing trend of refractive index $n$ with increasing $\lambda$ indicates the interactions between electrons in the studied material and the incident photons.

Also, The optical conductivity $\sigma_{\text {opt. }}$ of the prepared nanocomposite films can be calculated from the following equation, [15]: 
$\sigma_{o p t .}=\frac{\alpha n c}{4 \pi} \ldots \ldots(5), \alpha$ is the absorption coefficient, and $\mathrm{n}$ is the refractive index of the samples.

Fig. (8) illustrates the variation of optical conductivity $\boldsymbol{\sigma}_{\text {opt. }}$ as a function of photon energy $\boldsymbol{h v}$ for the investigated samples. It is observed that the optical conductivity increases with increasing the photon energy hv where the concentration and excitation of the electrons increase [19]. The largest optical conductivity value $\sigma_{\text {opt. }}$ was observed for the samples with $\mathrm{CoFe}_{2} \mathrm{O}_{4}$ content.

The complex dielectric constant reveals the basic intrinsic property of materials. The real part of dielectric constant is representing how much velocity of light slows down in the material, although imaginary part of dielectric constant represents how dielectric material absorbs energy from electric field due to dipole motion. The real and imaginary parts of dielectric constant have been calculated using the following equations [15], [20] [21].

$$
\begin{aligned}
& \varepsilon_{\mathrm{r}}=\mathrm{n}^{2}-\mathrm{k}^{2} \\
& \varepsilon_{\mathrm{i}}=2 \mathrm{nk} \ldots
\end{aligned}
$$

(7) where, $\varepsilon_{\mathrm{r}}$ is real part of dielectric constant, $\varepsilon_{\mathrm{i}}$ is imaginary part of dielectric constant.

Fig. (9: a-d) illustrate the real dielectric constant $\left(\boldsymbol{\varepsilon}_{\mathbf{r}}\right)$ as a function of $\lambda$, whereas imaginary dielectric constant $\left(\boldsymbol{\varepsilon}_{\mathbf{i}}\right)$ as a function of $\lambda$ represented by Fig. (9: e-h) of the investigated samples.

Fig.s (9: a-h) showed that the dielectric response of the $\mathrm{PVDF} /\left(\mathrm{Cu}-\mathrm{CoFe}_{2} \mathrm{O}_{4}, \mathrm{CoFe}_{2} \mathrm{O}_{4}\right.$, and $\mathrm{CuFe}_{2} \mathrm{O}_{4}$ ) has higher dielectric values at lower wavelength (higher energy) compared with pure PVDF. This increase caused by the interfacial polarizations at the conductor-insulator interface [22]. The higher occurrence of the polarization process in $\mathrm{PVDF} /\left(\mathrm{Cu}-\mathrm{CoFe}_{2} \mathrm{O}_{4}\right)$ sample can be due to the existence of a huge number of trap states at the grain boundaries of the synthesized samples. These trap states are produced due to the presence of vacancies or defects [23].

\section{3. $\mathrm{PVDF} /\left(\mathrm{Cu}-\mathrm{CoFe}_{2} \mathrm{O}_{4}, \mathrm{CoFe}_{2} \mathrm{O}_{4}\right.$, and $\left.\mathrm{CuFe}_{2} \mathrm{O}_{4}\right)$ Energy harvest performance}

The piezoelectric response of the prepared samples has been investigated using two different methods. The first one using a digital storage oscilloscope (DOS) and the other using piezo response force microscopy (PFM).

\subsubsection{Piezoelectric response using a digital storage oscilloscope (DOS)}


The working principle of the piezoelectric energy harvester of PVDF is based on the insulating property and the creation of an inner piezoelectric field under an applied force [24].

The prepared nanocomposite films have been tested using a digital storage oscilloscope (DOS), where each film was placed between two copper layers. With respect to the open circuit (with forward and reverse connection), the generated piezo potential was recorded because of a repetitive finger stress has been applied on the upper surface of nanocomposite films. The finger tapping generates a compressive stress on the surface of films, causes the displacement of positive and negative charges in the nanocomposite films.

It is well known that PVDF mainly have four phase structures, $\alpha$ phase, $\beta$ phase, $\gamma$ phase, and $\delta$ phase, depending on the chain conformations [25]. The alpha phase is the most energy stable, but it has very weak piezoelectric characteristics compared with the high polarity beta phase. The $\beta$ phase possesses the highest dipole moments, where PVDF has polymeric chain of repeated unit of $\left[\mathrm{CF}_{2}-\mathrm{CF}_{2}-\right.$ ]$_{n}$ monomers which consists of $\mathrm{CH}_{2}$ - positively charged dipoles and $\mathrm{CF}_{2}$ - negatively charged dipoles and as a result, best piezoelectric performance [26].

By mechanical deformation and polarization, the structure of alpha phase can be transformed into polar beta phase to achieve piezoelectric characteristics [27].

The nanoparticles improved the piezo-potential as shown in fig. (10, a-d) where an interaction between the $\mathrm{CoFe}_{2} \mathrm{O}_{4}, \mathrm{CuFe}_{2} \mathrm{O}_{4}$ and $\mathrm{Cu}-\mathrm{CoFe}_{2} \mathrm{O}_{4}$ nanoparticles and the dipoles of PVDF. The largest recorded output voltage has been observed in the PVDF/ $\mathrm{CoFe}_{2} \mathrm{O}_{4}$ film sample, as shown in Fig. (10, b).

This enhancement of piezo-potential in PVDF composite films is due to the role of $\mathrm{CoFe}_{2} \mathrm{O}_{4}$, $\mathrm{CuFe}_{2} \mathrm{O}_{4}$ and $\mathrm{Cu}-\mathrm{CoFe}_{2} \mathrm{O}_{4}$ nanofillers in PVDF matrix, which is provide a conducting particle could help charges induced inside the film to move to the film surface. Also, the interaction between $\mathrm{Co}^{2+}$, $\mathrm{Cu}^{2+}$ and $\mathrm{Fe}^{3+}$ nanoparticles with $\mathrm{CF}_{2^{-}}$dipoles and $\mathrm{O}^{2-}$ nanoparticles of $\mathrm{CoFe}_{2} \mathrm{O}_{4}, \mathrm{CuFe}_{2} \mathrm{O}_{4}$ and $\mathrm{Cu}-$ $\mathrm{CoFe}_{2} \mathrm{O}_{4}$ with $\mathrm{CH}_{2}$ - dipoles could enhance the piezo response of PVDF polymer.

It can be noted that the PVDF composite films with higher values of complex dielectric constant ( $\mathrm{PVDF} / \mathrm{CoFe} \mathrm{O}_{4}$ and PVDF/Cu-CoFe $\mathrm{O}_{4}$ ), has the higher values of piezo potential Fig. (9, 10). As the polarization causes a slight increase in the dielectric constant, where the beta phase dipoles rearranged and a transformation of alpha to beta takes place when energy is applied [28]. 


\subsubsection{PFM studies}

Another tool to investigate the piezoelectric response of the particles, piezoresponse force microscopy (PFM) was used. This technique is based on a standard scanning force microscope (SFM), operated in contact-mode with an alternating voltage Va.c applied to the tip resulting in an alternating electric field inside the sample. In the case of piezoelectric samples, the samples undergo a periodic deformation, taking along the tip. Such deformation can take place in any directions, therefore leading to deflection, buckling, or torsion of the cantilever [29]. Deflection is the consequence of an out of plane deformation (a change in the z-axis), buckling responds to an in-plane deformation (a diameter change in the y-axis) as well as torsion is related to another in-plane deformation (a length change in the $\mathrm{x}$-axis). PFM consequently allows a highly resolved lateral mapping of the piezoelectric properties of the investigated sample. The domain structures can be obtained using piezo response force microscopy (PFM) by combining the in-plane and out-of-plane PFM images [30].

The pure PVDF and PVDF/(Cu-CoFe $2 \mathrm{O}_{4}, \mathrm{CoFe}_{2} \mathrm{O}_{4}$, and $\left.\mathrm{CuFe}_{2} \mathrm{O}_{4}\right)$ nanocomposites films with the area of $2.5 \mu \mathrm{m} \times 2.5 \mu \mathrm{m}$ was scanned with alternating Vac of $510 \mathrm{mV}$ applied to the cantilever tip. Fig. (11:a-l) showed the PFM responding in the z-axis direction, phase and amplitude micrographs of the investigated samples, respectively. The out of plane PFM phase images Fig. (11:a, d, g and j) for all samples, corresponding to the piezoelectric polarization, both negative (white) and positive (black) areas appeared indicating antiparallel ferroelectric nanodomains with $180^{\circ}$ domain walls. The white areas correspond to negative domains with the polarization direction perpendicular to the surface of the PVDF film and oriented downward, while the black areas correspond to positive domains having the polarization direction oriented upward [31] [32]. In Fig. (11, a) the well-defined piezoelectric domains demonstrate that the elongated crystallites are the homogeneous $\beta$-phase. The PFM amplitude (Fig. 11, $\mathrm{b}$ and c) a piezoelectric contrast due to the defections caused by the applied alternating field has been noted. Therefore, the domains in the PVDF film align along the z-axis direction perpendicular to the sample and the bottom electrode, Fig. (12).

The in-plane PFM images (Fig.11: d-j) were analyzed both for the phase and amplitude dependence of the PFM signal of PVDF/(Cu-CoFe $\mathrm{O}_{4}, \mathrm{CoFe}_{2} \mathrm{O}_{4}$, and $\left.\mathrm{CuFe}_{2} \mathrm{O}_{4}\right)$ nanocomposites films. The images Fig. $(11,12)$ reveal the formation of periodic stripe domains acquired at $\theta=0^{\circ}$. All the images of $\mathrm{PVDF} /\left(\mathrm{Cu}-\mathrm{CoFe}_{2} \mathrm{O}_{4}, \mathrm{CoFe}_{2} \mathrm{O}_{4}\right.$, and $\left.\mathrm{CuFe}_{2} \mathrm{O}_{4}\right)$ nanocomposites films show stripe domains aligned along the last saturating field direction. 
In Fig. (11: d-f) the PVDF/ $\left(\mathrm{CoFe}_{2} \mathrm{O}_{4}\right)$ sample indicating that the nano domains merged into micro sized domains, the nano domains merged into one micro sized domain, supported by the cross-section phase variation.

\section{Conclusion}

Cobalt ferrite, Copper ferrite and cobalt doped copper ferrite nanoparticles have been synthesized and characterized. The prepared $\mathrm{Cu}-\mathrm{CoFe}_{2} \mathrm{O}_{4}, \mathrm{CoFe}_{2} \mathrm{O}_{4}$, and $\mathrm{CuFe}_{2} \mathrm{O}_{4}$ nanoparticles have been introduced to the PVDF polymer.

PVDF optical and piezoelectric properties have been studied using three nanofillers, (Co, $\mathrm{Cu}$ and $\mathrm{Co} / \mathrm{Cu}$ ) ferrite. This study showed that the PVDF polymer optical properties has improved by introducing the prepared nanoparticles, The dielectric constant of the PVDF polymer increased dramatically from $2.3 \times 10^{4}$ to $9.9 \times 10^{9}$ in $\mathrm{PVDF} /\left(\mathrm{Cu}-\mathrm{CoFe}_{2} \mathrm{O}_{4}\right)$ nanocomposite. As well as the pure PVDF optical conductivity increased five times by adding $\left(\mathrm{Cu}-\mathrm{CoFe}_{2} \mathrm{O}_{4}\right.$ and $\left.\mathrm{CoFe}_{2} \mathrm{O}_{4},\right)$.

Also, The prepared nanoparticles enhanced the PVDF piezoelectricity, the PVDF/(Cu-CoFe ${ }_{2} \mathrm{O}_{4}$, $\mathrm{CoFe}_{2} \mathrm{O}_{4}$, and $\mathrm{CuFe}_{2} \mathrm{O}_{4}$ ) nanocomposites films show stripe domains aligned along the last saturating field direction when examined using PFM., the domains in the PVDF film align along the $\mathrm{z}$-axis direction perpendicular to the sample and the bottom electrode. 


\section{$\underline{\text { References }}$}

[1] A. Banica, Energy Harvesting from Renewable Energy Sources., Proceedings of the International Conference of Mechatronics and Cyber-MixMechatronics , (2020), pp. 247254.

[2] J. Z. C. L. S.-W. L. a. L. L. Huicong Liu, "A comprehensive review on piezoelectric energy harvesting technology: Materials, mechanisms, and applications," Applied Physics Reviews 5, p. 041306, 2018.

[3] V. R. G. M. V. L. B. P. B. X. Haque Rubaiyet Iftekharul, "Inkjet Printing of High Molecular Weight Pvdf-Trfe for Flexible Electronics," Flexible and Printed Electronics, vol. 1, p. 01500, 2016.

[4] B. J. W. K. a. S. B. K. Mahadeva Suresha, "'Effect of Poling Time and Grid Voltage on Phase Transition and Piezoelectricity of Poly(Vinyledene Fluoride) Thin Films Using Corona Poling," Journal of Physics D: Applied Physics, vol. 46, no. 2, p. 285305, 2013.

[5] T. V. T. H. a. T. A. B. Daniel A. Porter, "Effects of in-Situ Poling and Process Parameters on Fused Filament Fabrication Printed Pvdf Sheet Mechanical and Electrical Properties," Additive Manufacturing, vol. 13, pp. 81-92., 2017.

[6] Q. C. X. S. L. D. Z. W. Wenying Zhou, "Enhanced thermal conductivity and dielectric properties of Al/ $\beta-S i C w / P V D F$ composites,," Composites Part A: Applied Science and Manufacturing,, vol. 71, pp. 184-191, 2015.

[7] J. Q. H. J. K. Z. J. W. Lu Yang, "Enhanced dielectric and ferroelectric properties induced by TiO2@MWCNTs nanoparticles in flexible poly(vinylidene fluoride) composites,," Composites Part A: Applied Science and Manufacturing, vol. 65, pp. 125-134, 2014.

[8] I. M. a. G.Bertotti, "Hysteresis in Piezoelectric and Ferroelectric Materials," in The Science of Hysteresis, Elsevier, 2005.

[9] M. Haponska, A. Trojanowska, A. Nogalska, R. Jastrzab, T. Gumi and B. Tylkowski, "PVDF Membrane Morphology-Influence of Polymer Molecular Weight and Preparation Temperature," Polymers, vol. 9, p. 718, 2017.

[10] M. A. R. M. a. J. M. Sasaki, "The limit of application of the Scherrer equation," Acta Cryst. , vol. A74, pp. 54-65, 2018.

[11] R. Ramadan, "Physical study of cobalt ferrite and its application in purification of water," Phys. A, vol. 125, p. 825, 2019.

[12] K. R. N.B. Singh, "Copper ferrite-Polyaniline nanocomposite and its application for Cr (VI) ion removal from aqueous solution," Environmental Nanotechnology, Monitoring \& 
Management, vol. 14, p. 100301, 2020.

[13] P. K. T. I. R. L. F. E. P. E. P. A. J. I. A. D. a. J. N. L. Hypolite Mathias Kamta TedjieukengORCID logo*a, "Structural characterization and magnetic properties of undoped and copper-doped cobalt ferrite nanoparticles prepared by the octanoate coprecipitation route at very low dopant concentrations," RSC Adv, vol. 8, pp. 38621-38630, 2018.

[14] V. S. S. Kirankumar, "Photocatalytic and antibacterial activity of bismuth and copper codoped cobalt ferrite nanoparticles.," J Mater Sci: Mater Electron , vol. 29, p. 8738-8746, 2018.

[15] S. T. N. K. Ajay Vasudeo Rane, Microscopy Applied to Materials Sciences and Life Sciences, CRC Press, 2018.

[16] R. P. Kamel A. Abd-Elsalam, Nanobiotechnology Applications in Plant Protection, Springer Nature, 2019.

[17] M. M. S. F. A.M. Ismail, "Optical and structural properties of polyvinylidene fluoride (PVDF) / reduced graphene oxide (RGO) nanocomposites," Journal of Molecular Structure, Vols. 1170,, pp. 51-59, 2018.

[18] G. D. D.J. Bhagat, "UV-VIS spectroscopic studies of one pot chemically synthesized polyindole/poly(vinyl acetate) composite films," Materials Letters, vol. 136, pp. 251-253, 2014.

[19] A. A. Kokhanovsky, Light Scattering Reviews 2, Springer Science \& Business Media. , 2007.

[20] H. S. Nalwa, Handbook of Advanced Electronic and Photonic Materials and Devices: Ferroelectrics and dielectrics, Academic Press, 2001.

[21] V. J. a. V. S. P. Stoller, "Measurement of the complex dielectric constant of a single gold nanoparticle," Optics Letters, vol. 31, no. 16, pp. 2474-2476, 2006.

[22] J. K. T. K. J. W. S. H. C. J. J. J. H. L. I. N. K. D. A. R. S. Ruoff, "Enhanced Dielectric Performance in Polymer Composite Films with Carbon Nanotube-Reduced Graphene Oxide Hybrid Filler," vol. 10, no. 16, pp. 3405-3411, 2014.

[23] K. K. a. V. Alexandrov, "Effect of intrinsic point defects on ferroelectric polarization behavior of SrTiO3," Physical Review B, no. American Physical Society, 2017.

[24] S. G. ,. S. S. a. D. M. Santanu Jana, "The influence of hydrogen bonding on the dielectric constant and the piezoelectric energy harvesting performance of hydrated metal salt mediated PVDF films," Phys.Chem.Chem.Phys., vol. 17, pp. 17429-17436, 2015.

[25] A. S. A. A. Yousefi, " Conformational changes and phase transformation mechanisms in PVDF solution-cast films.," J. Polym. Sci. B Polym. Phys., vol. 42, pp. 3487-3495, 2004. 
[26] M. B. N. a. J. B. S. M. Nakhmanson, "Ab Initio Studies of Polarization and Piezoelectricity in Vinylidene Fluoride and BN-Based Polymers," Phys. Rev. Lett. , vol. 92, p. 115504, 2004.

[27] A. A. Y. S. M. B. Behzad Mohammadi, "Effect of tensile strain rate and elongation on crystalline structure and piezoelectric properties of PVDF thin films," Polymer Testing, vol. 26, no. 1, pp. 42-50, 2007.

[28] Y. H. M. Z. Q. W. M. Z. a. H. Y. Jing Fu, "Improving Dielectric Properties of PVDF Composites by Employing Surface Modified Strong Polarized BaTiO3 Particles Derived by Molten Salt Method," ACS Applied Materials \& Interfaces, vol. 7, no. 44, pp. 24480-24491, 2015.

[29] V. S. K. A. S. V. Vasileva D, "Domain Diversity and Polarization Switching in Amino Acid $\beta$ Glycine. 2019 Apr 15;. doi: 10.3390/ma12081223. PMID: 30991625; PMCID: PMC6514944.," Materials (Basel)., vol. 12, no. 8, p. 1223, 2019.

[30] S. X. X. K. D. T. a. X. W. Xia Liu, "Nanoscale investigations on $\beta$-phase orientation, piezoelectric response, and polarization direction of electrospun PVDF nanofibers," RSC Advances, vol. 6, no. 110, pp. 109061-109066, 2016.

[31] Z. C. Q. H. J. D. C. C. R. S. A. K. Y. M. E. N. Z. F. L. Y. X. G. D. Z. L. C. A. Y. B. S. S. J.-M. L. a. J. B. Deyang Chen, "Interface Engineering of Domain Structures in BiFeO3 Thin Films," Nno letters, vol. 17, no. 1, pp. 486-493, 2017.

[32] H. C. B. C. R. C. G. D. B. F. S. a. M. S. S. M. Fortunato, "PFM Characterization of PVDF Nanocomposite Films With Enhanced Piezoelectric Response," IEEE Transactions on Nanotechnology, vol. 17, no. 5, pp. 955-961, 2018. 
Figures

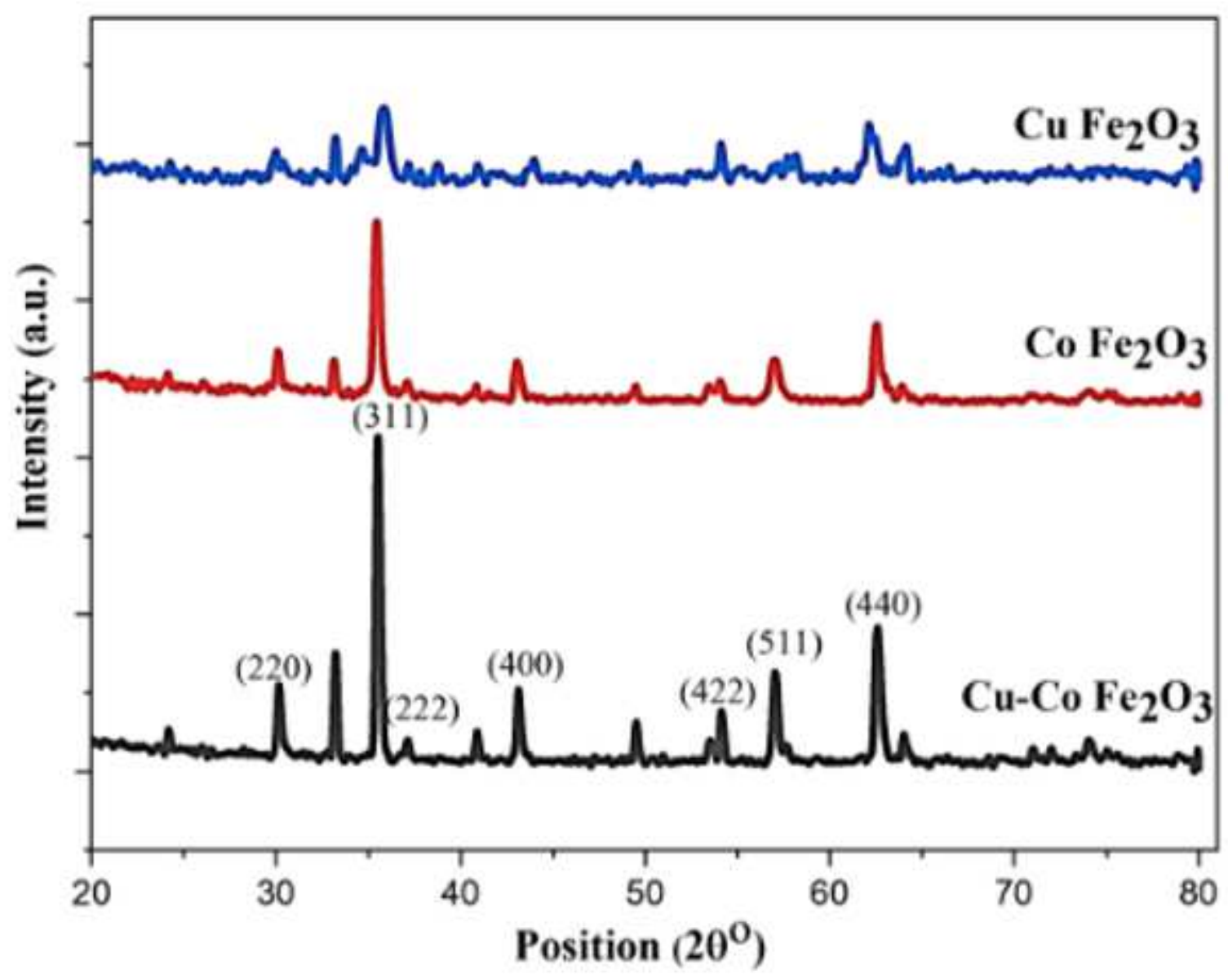

Figure 1

XRD pattern of CoFe2O4, CuFe2O4 and Cu-CoFe2O4 nanoparticles. 


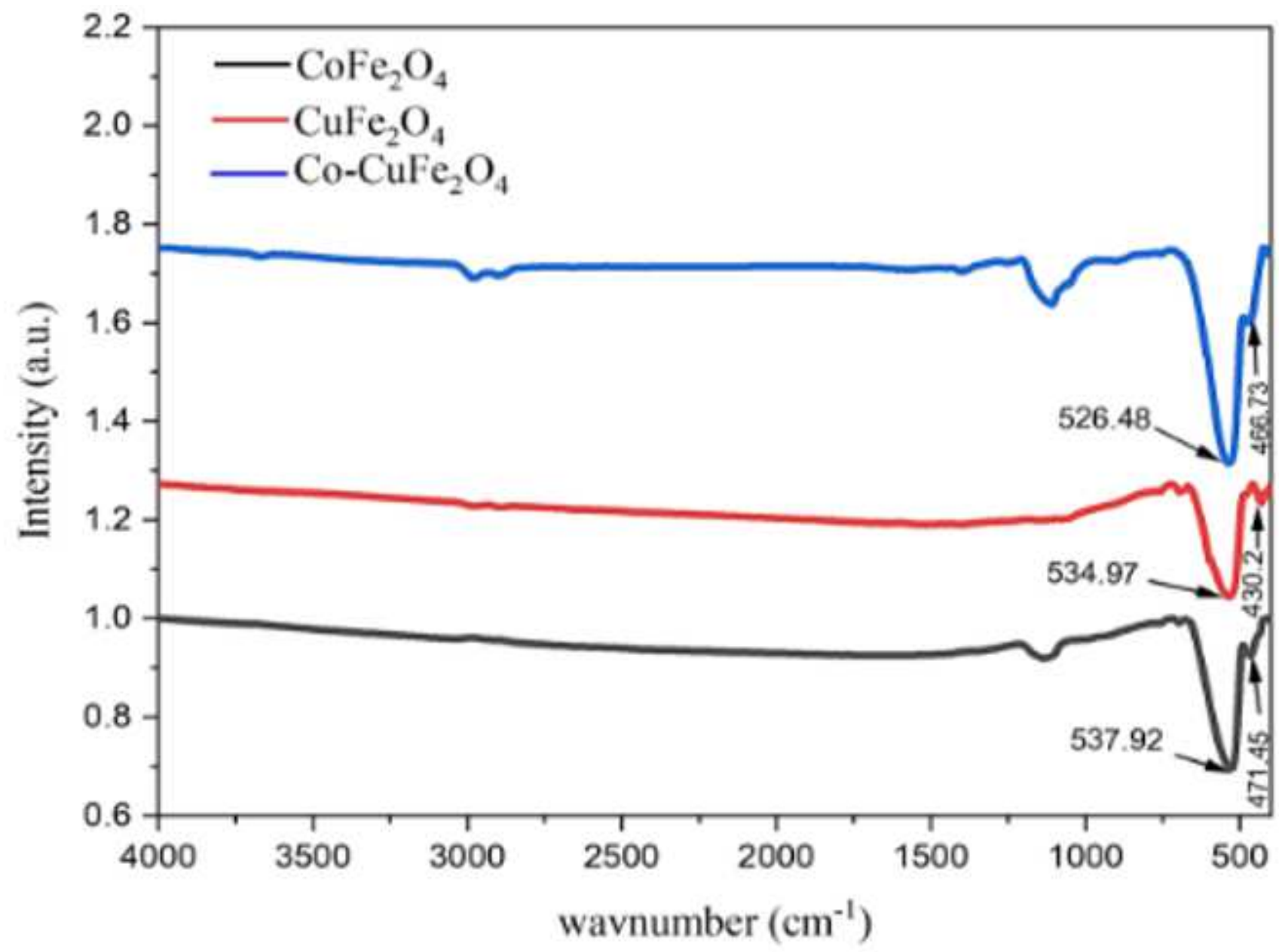

Figure 2

FTIR spectrum of CoFe2O4, CuFe2O4 and Cu-CoFe2O4 nanoparticles. 

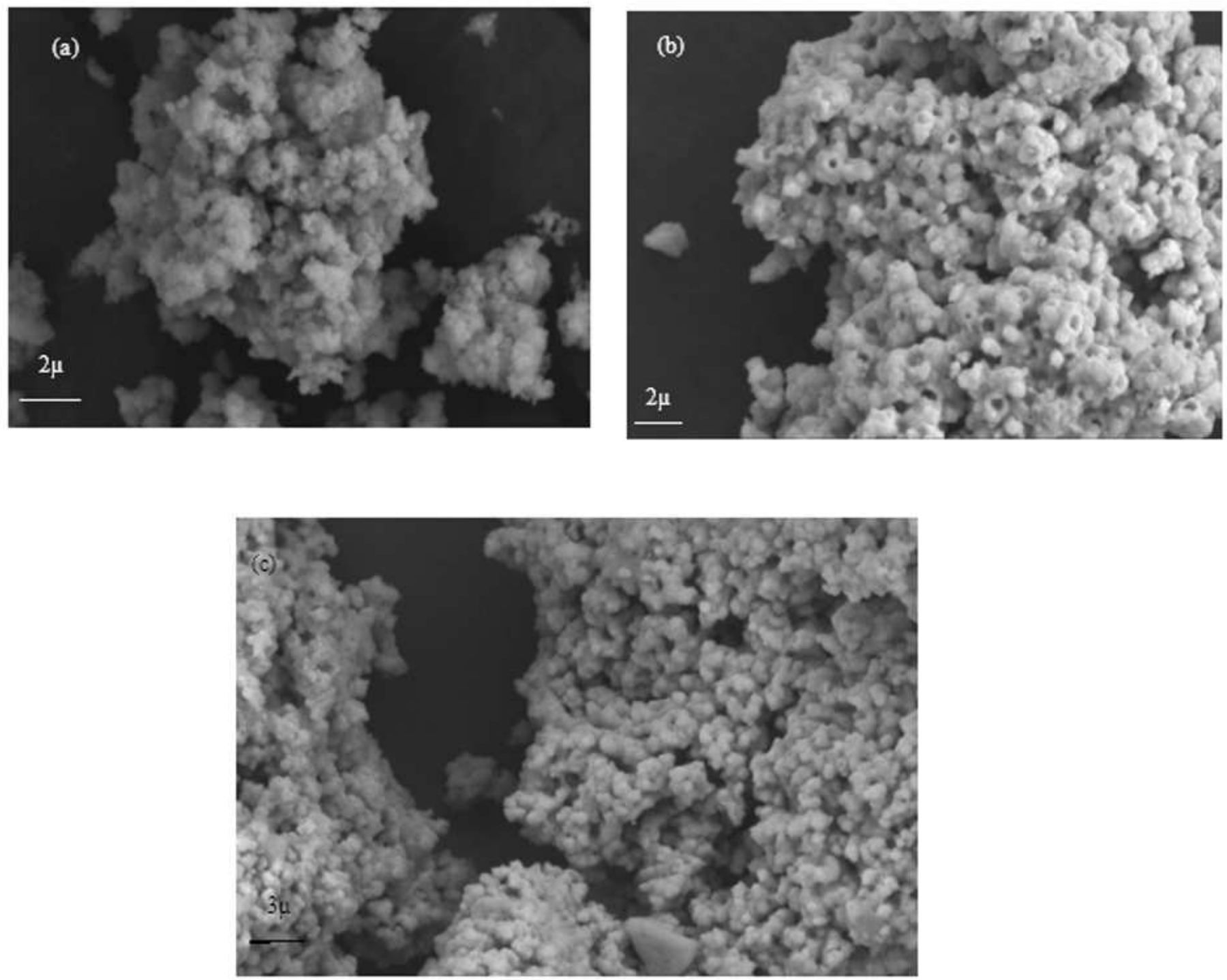

Figure 3

a,b and c): FESEM micrographs of CoFe204, CuFe2O4 and Cu-CoFe2O4 nanoparticles 


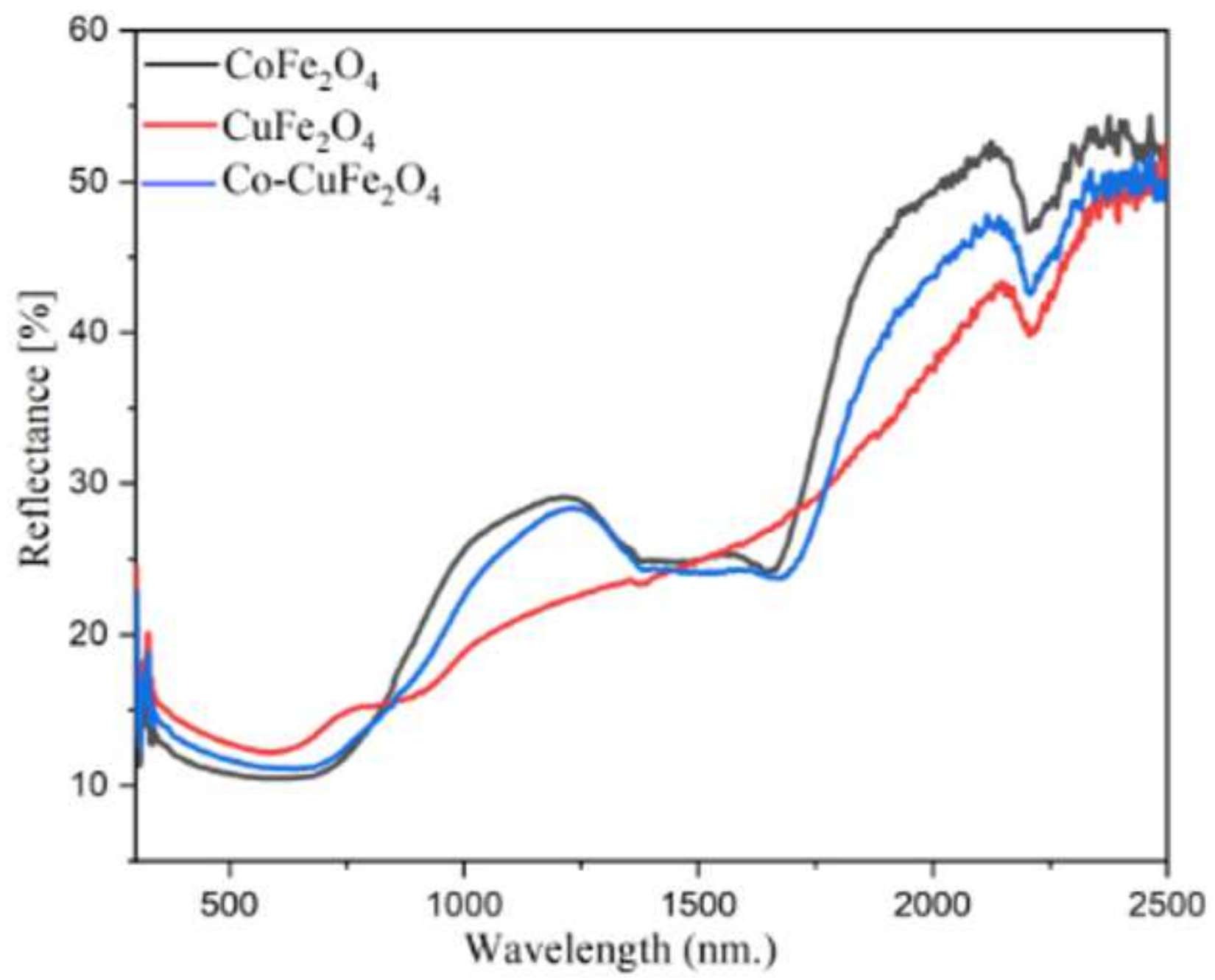

Figure 4

Reflectance of UV-Vis. spectrum of CoFe2O4, CuFe2O4 and Cu-CoFe2O4
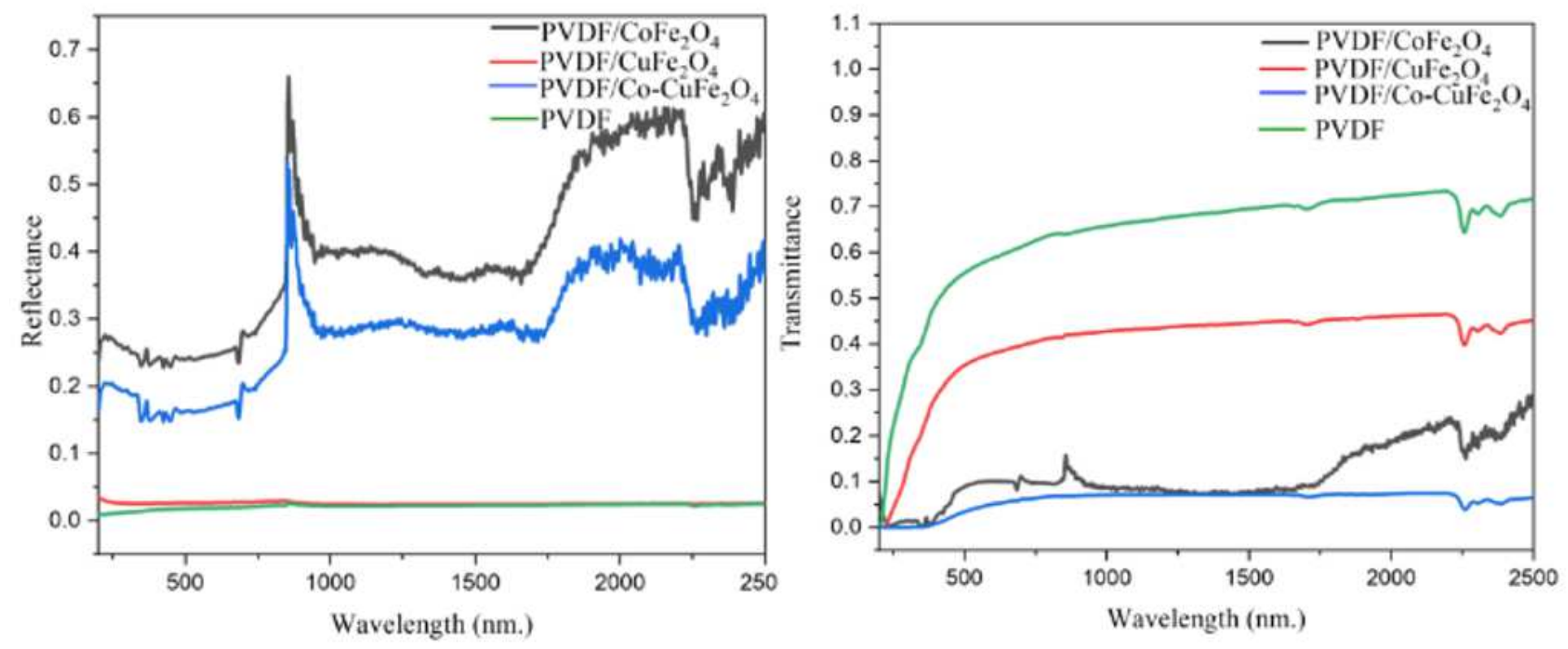
Figure 5

(a) Reflectance of UV-Vis. Spectrum of PVDF/(Cu-CoFe204, CoFe2O4, and CuFe2O4), (b) Transmittance of UV-Vis. Spectrum of PVDF/(Cu-CoFe2O4, CoFe2O4, and CuFe2O4)
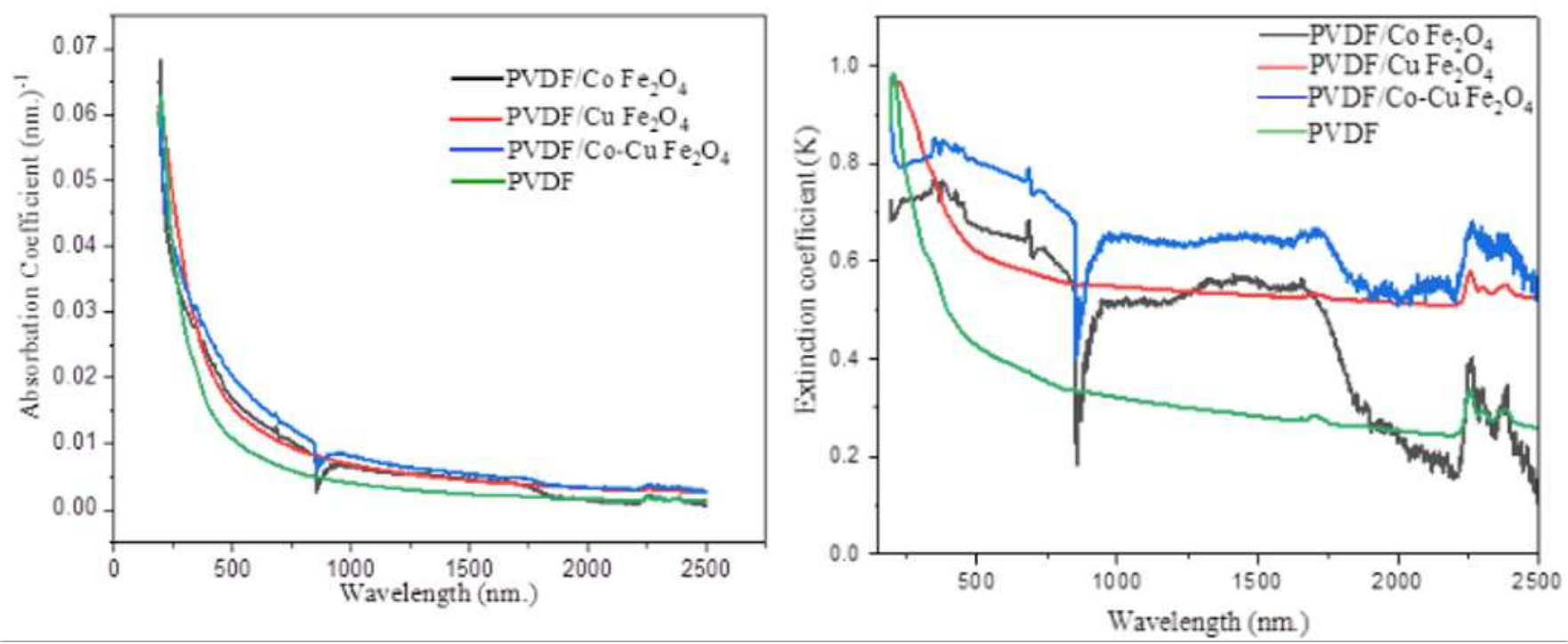

Figure 6

(a) Absorption coefficient of PVDF/(Cu-CoFe2O4, CoFe2O4, and CuFe2O4), (b) Extinction coefficient of $\mathrm{PVDF} /(\mathrm{Cu}-\mathrm{CoFe} 2 \mathrm{O4}, \mathrm{CoFe2O4}$, and CuFe2O4

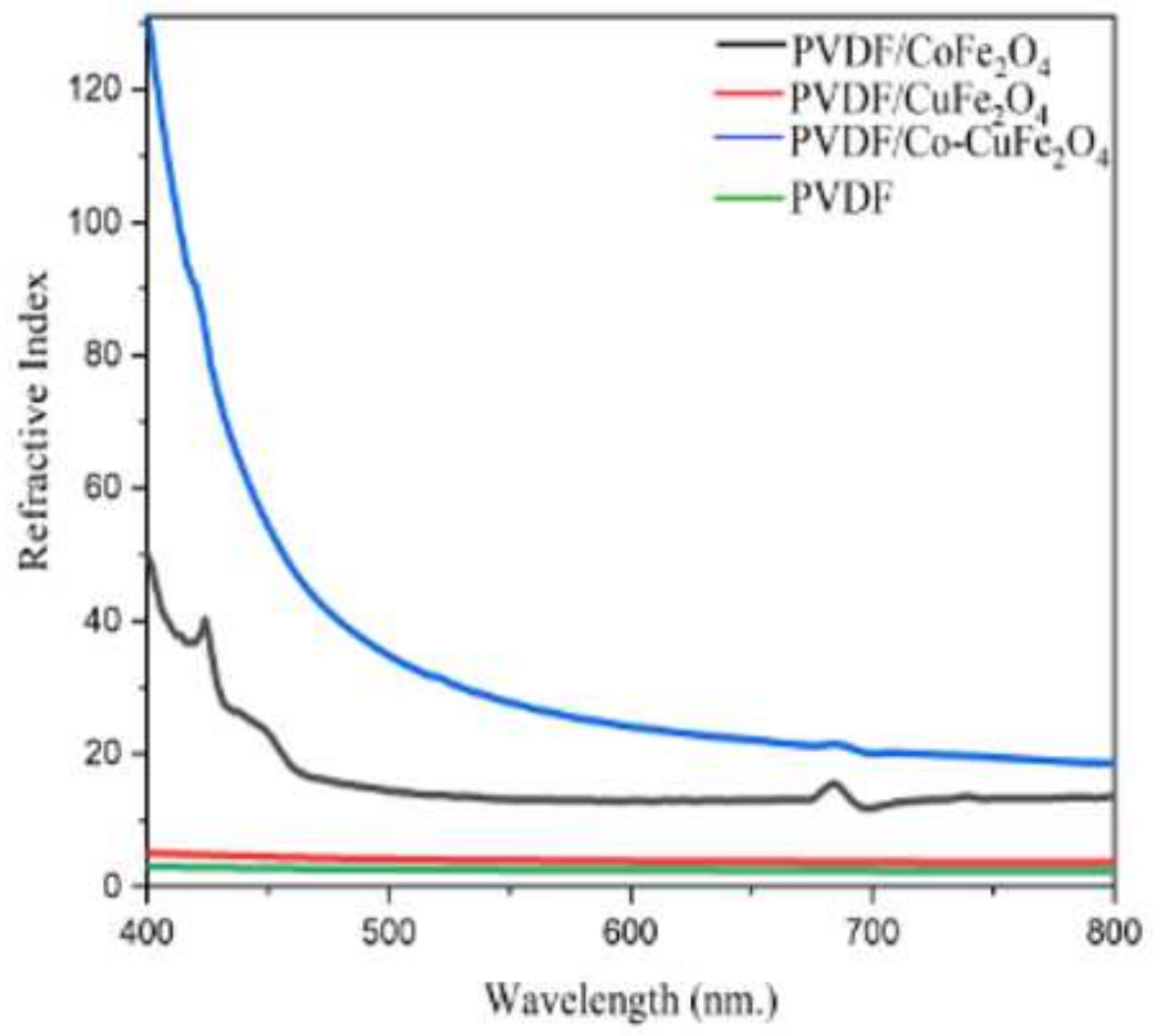


Figure 7

Refractive index of PVDF/(Cu-CoFe204, CoFe2O4, and CuFe2O4),

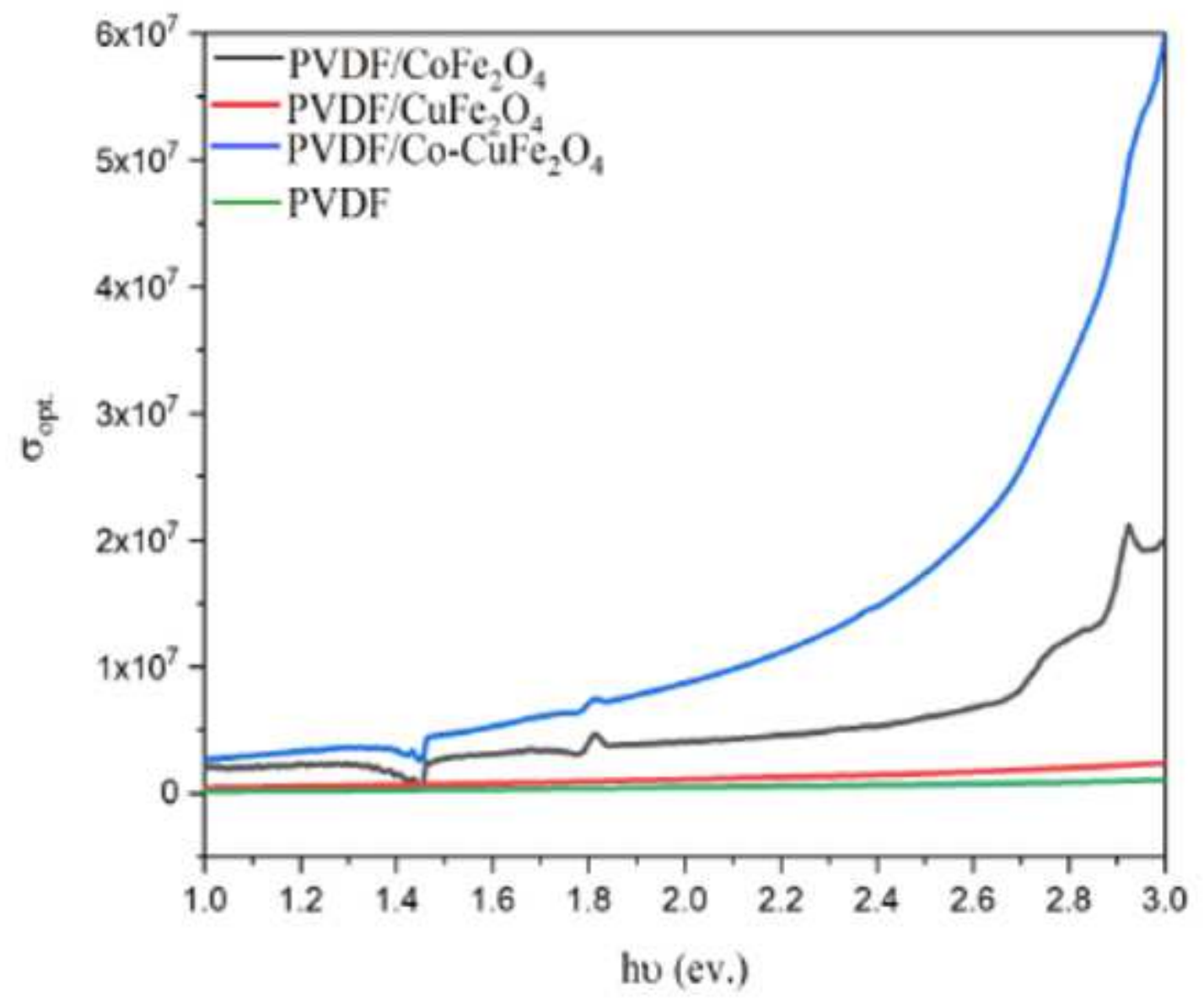

Figure 8

Optical conductivity of PVDF/(Cu-CoFe2O4, CoFe2O4, and CuFe2O4 

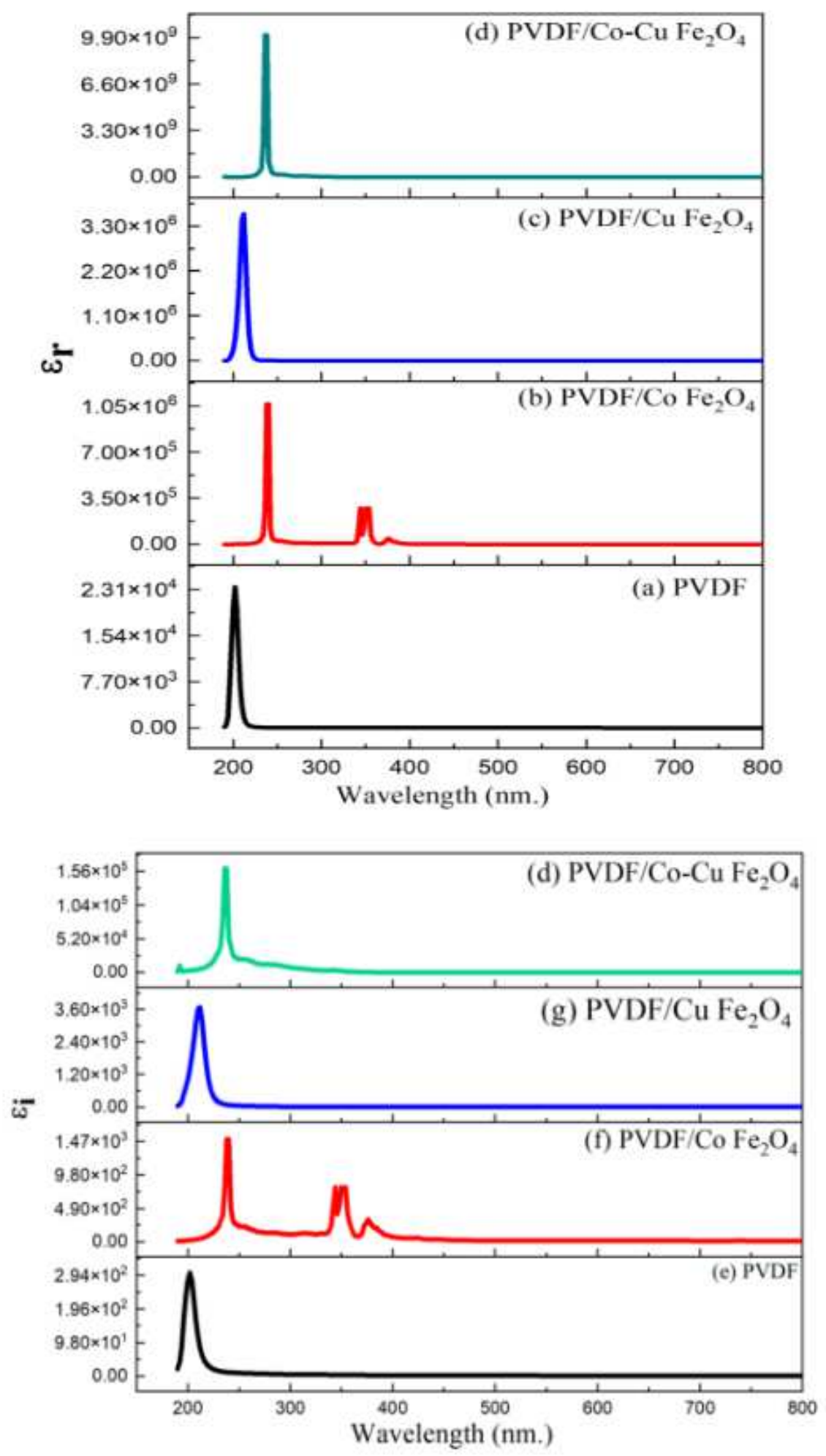

\section{Figure 9}

(a-d) Real dielectric constant of PVDF/(Cu-CoFe2O4, CoFe2O4, and CuFe204), (e-h) Imaginary dielectric constant of PVDF/(Cu-CoFe2O4, CoFe2O4, and CuFe2O4) 

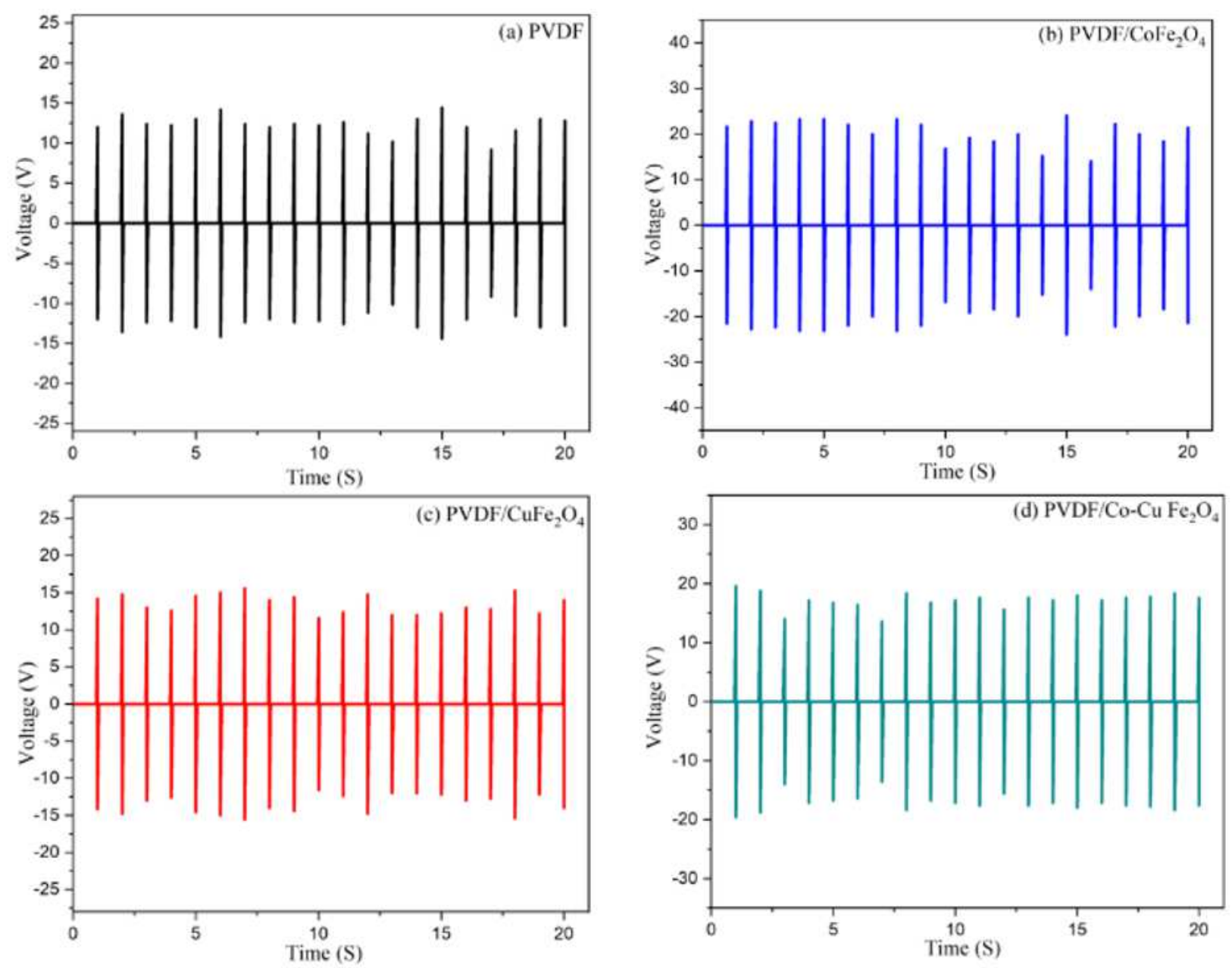

Figure 10

a-d): Open-circuit output voltages from PVDF/(Cu-CoFe2O4, CoFe204, and CuFe2O4) nanocomposite films during repetitive impact by a human's finger. 
PVDF
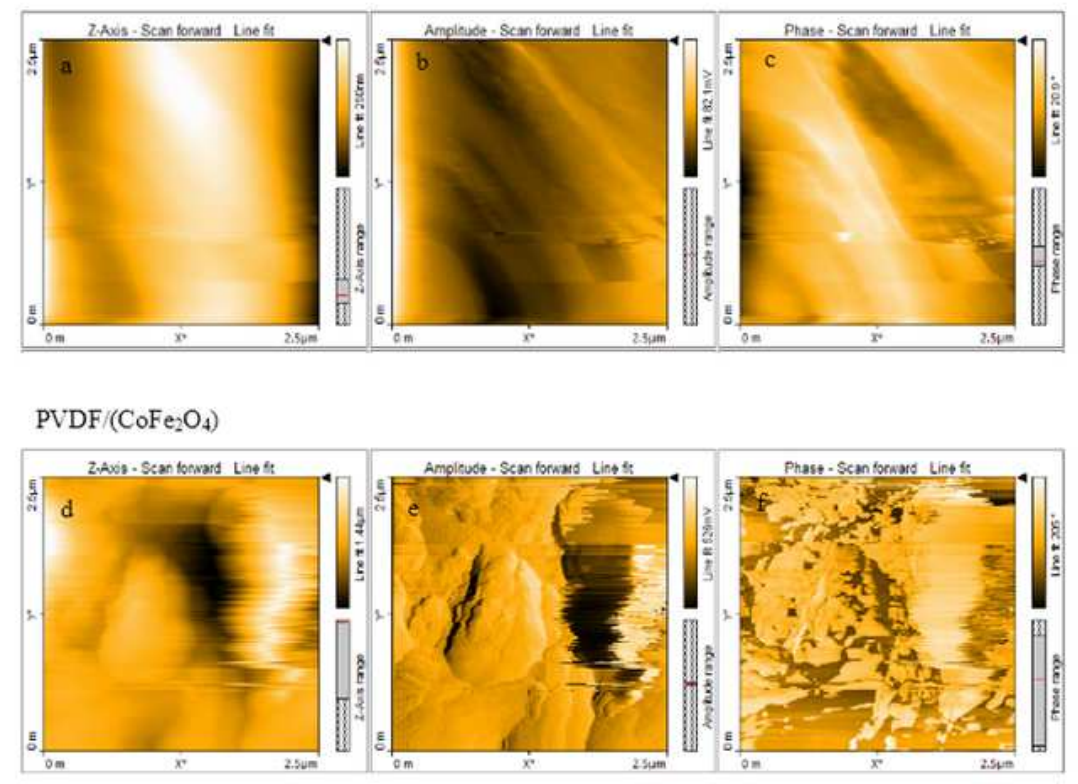

$\mathrm{PVDF} /\left(\mathrm{CuFe}_{2} \mathrm{O}_{4}\right)$

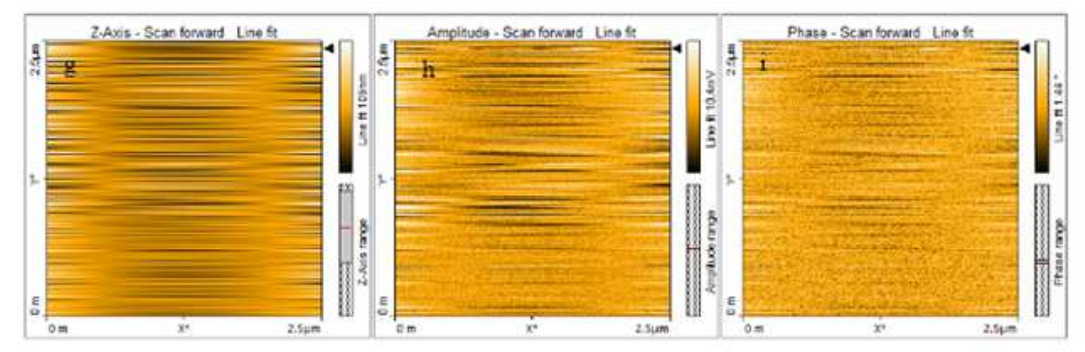

$\mathrm{PVDF} /\left(\mathrm{Cu}-\mathrm{CoFe}_{2} \mathrm{O}_{4}\right)$

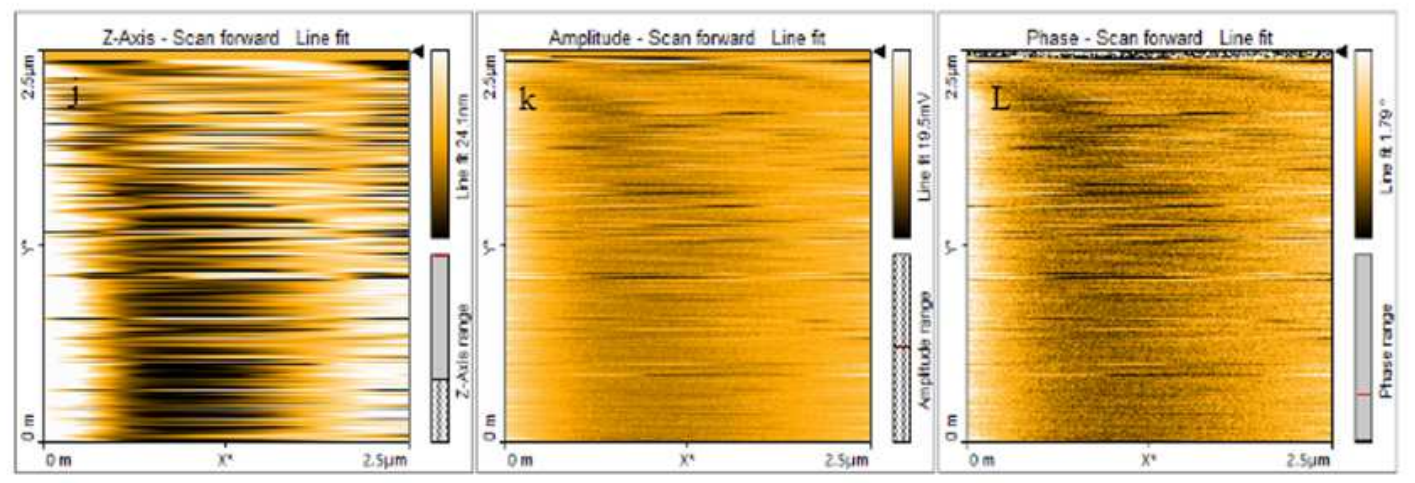

Figure 11

Z-axis direction, phase and amplitude PFM micrographs of PVDF/(Cu-CoFe2O4, CoFe2O4, and CuFe2O4) nanocomposite films. 

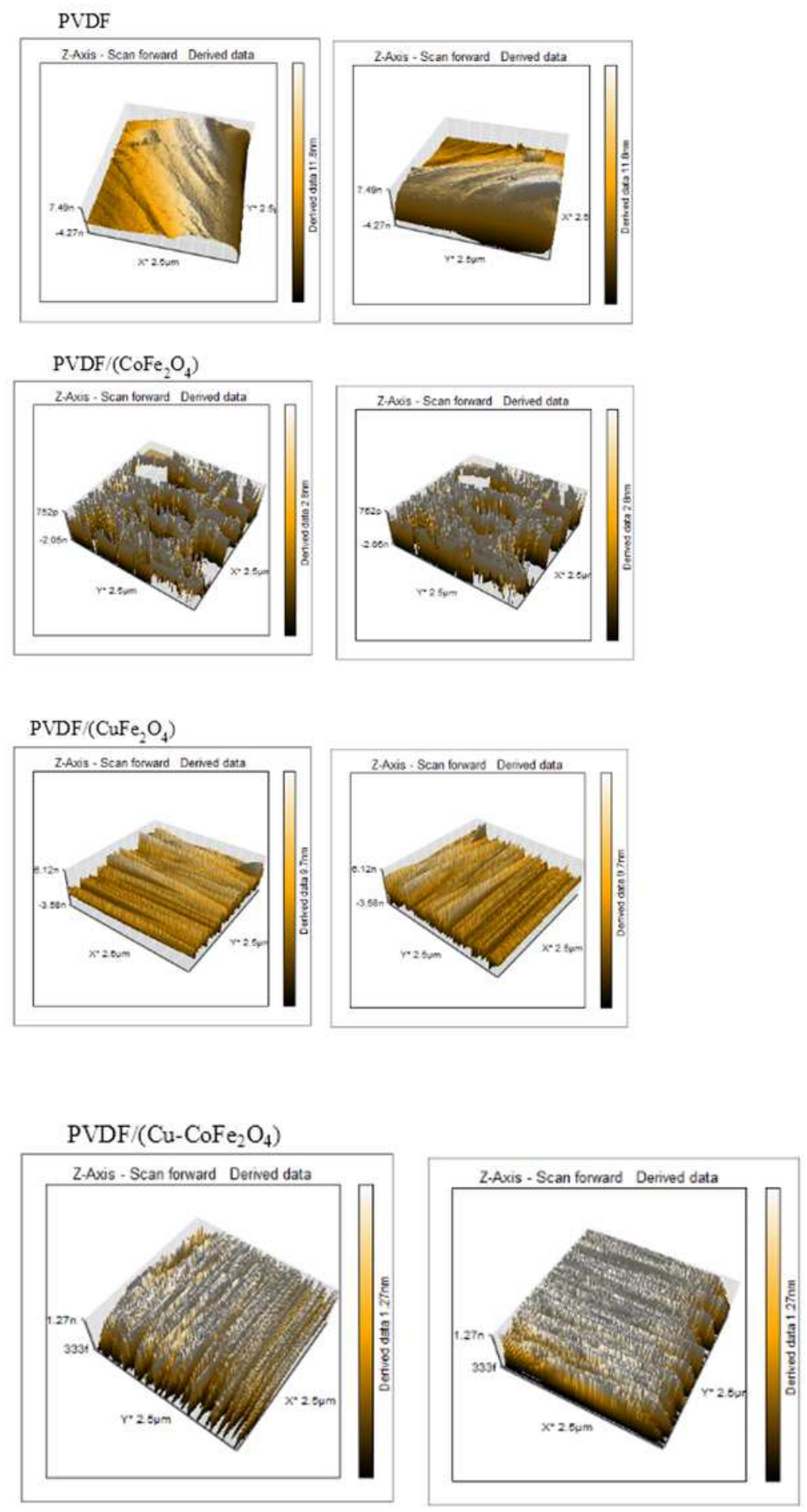

\section{Figure 12}

Z-axis direction derived data PFM micrographs of PVDF/(Cu-CoFe2O4, CoFe2O4, and CuFe2O4) nanocomposite films. 